So far, no case of sarcoidosis has been reported with painful tumours. It is also extremely rare to see a case of mixed sarcoid as mine with uveitis and subconjunctival tumour at the same time. Almost a similar case of Boeck's sarcoidosis of the lacrimal gland has been reported by Stallard, but there was no uveitis. And a number of cases of Boeck's iritis have been published, but not with an orbital tumour in any.

The fortuitous onset of the disease in my patient is rather unfortunate as having occurred after the cataract extraction with which it has no aetiological connection, though I am thankful to the mishap as it brought back the patient with this rare disorder.

Diagnosis.-The question of Hodgkin's disease can easily be ruled out as it is a disease of young adult males: No lymphatic glands are enlarged; spleen is normal; no anaemia-except for the recent slight occasional pyrexia, the so-called Pel-Ebstein's fever did not occur at the onset. On the whole there is no appearance of malignancy or impending fatality to suggest the similar reticulo-endothelial disorder. Though radiologically positive, I consider the chest lesions are healed sarcoidosis of the lung.

The only other disease simulating sarcoid is uveo-parotid fever. I have not so far seen a case though a lot of literature has been published. In fact sarcoidosis includes very often in its symptomatology Heerfordt's syndrome. The more common generalised glandular involvement, facial paralysis and the initial high fever being absent in my case leaves uveo-parotid fever out of consideration.

Though the slight pyrexia, the roentgenological adenopathy, absence of caseation and the weak or negative Mantoux, common characteristics of sarcoid and uveo-parotid were present in my case, the added subconjunctival tumour, the dermopathy along with the uveitis clinches the diagnosis of sarcoid.

\title{
ANNOTATION
}

\section{Cacoethes Scribendi}

It was announced not long ago in the papers that the Minister of Supply wishes to reduce the number of forms which have to be filled in by those firms engaged in war production. Many will hear this news with relief, for form filling is rather a nightmare to most people; and if this concession could be applied to all government forms, including our income-tax returns, it would be welcome. But we must say that will not be an easy matter to manage.

We understand that it is impossible to order a pair of spectacles for a soldier without entering details in quadruplicate. We suppose 
that it is not possible to escape this enormous amount of clerical work which falls on the man who tests the vision and is responsible for the actual refraction, but we should have thought that in matters ophthalmological the army authorities might have taken a lesson from Moorfields Hospital, where the details have only to be entered on the out-patient card or in-patient sheet as the case may be, and the prescription filled in on the official form. But it would seem that, in the army, form filling is no new thing. Sir W. H. Russell, the celebrated war correspondent of The Times in his book on the British Expeditionary Force in the Crimea (1888) has a good deal to say about it. " Lord Raglan," he writes, "went out to one or other of his divisions every day he could spare from his desk. Perhaps there was no clerk in England who had so much writing to get through, ipsa manu, as the Field Marshal in command of the Forces. I believe his Lordship was frequently up till 2 or 3 in the morning, looking over papers, signing documents, preparing orders and despatches, and exhausting his energies in secretary's work. Such a life could with most men afford little opportunity for energy and action. The system that necessitates such labours on the part of the commander in chief must be faulty; it certainly was unsuited for the field and for times of war and was antiquated and cumbrous. The requirements of home authorities obliged the heads of departments to do a great deal of writing. They had to fill up innumerable forms, requisitions, abstracts and returns, and every motion in the House for papers overwhelmed them with fresh matter for pen, ink and paper." Of General Sir James Simpson, we find on page 541, "The general was a victim to writing like his predecessor. He was more a clerk than a general. Now is it the Horse Guards which enforces all this scrivening? If the army cannot be commanded without all these forms and returns let us have in future a writing general and a fighting general."

If Lord Beaverbrook can manage to simplify the herculean task of form filling he will earn the gratitude of everybody.

\section{ANNUAL CONGRESS OF THE OPHTHALMOLOGICAL SOCIETY OF THE UNITED KINGDOM}

The Annual Congress of the Society was held in Trinity College, Cambridge, by courtesy of the Master and Fellows, on Thursday and Friday, September 4 and 5,1941. Considering the difficulties of arrangement, there was a very good attendance of some eighty members.

In opening the Congress, the President, Mr. R. Affleck Greeves, 